\title{
The effect of the home cage environment on retention of an active avoidance response in previsual rats
}

\author{
JAMES R. MISANIN, LARRY E. TURNS, and NANCY A. LARIVIERE \\ Susquehanna University, Selinsgrove, Pennsylvania \\ and \\ CHARLES F. HINDERLITER \\ University of Pittsburgh, Johnstown, Pennsylvania
}

\begin{abstract}
Ten-day-old rats trained on multidirectional active avoidance response in a shock well showed no evidence of retention of the response $30 \mathrm{~min}$ after training if they were returned to the home cage during the retention interval. In contrast, rat pups that were maintained in a temperaturecontrolled chamber showed some retention of the response. Potential differences in arousal level may account for the differential effects of the retention interval manipulations.
\end{abstract}

There is ample evidence that rats younger than 2 weeks of age have difficulty retaining an active avoidance response (AR) even at short time intervals. Spear and Smith (1978), for example, found no 24-h retention in 7-12-day-old rats whose memories were not reactivated during the retention interval. Similarly, Goldman and Tobach (1967), who were the first to examine retention of avoidance behavior in previsual rats, provide no convincing evidence of 24-h retention. Ten- and 13-day-old rats were given 3 successive days of training on an active $\mathrm{AR}$, and the 10-day-olds made fewer ARs on their 3rd day of training than the 13-day-olds on their 1st day of training, suggesting that day-to-day improvements were maturational rather than memorial in nature. More recently, Misanin, Turns, and Hinderliter (in press) found that, although the retentive memory capacity of 10-day-old rats was sufficient to sustain memory beyond the training session, a retention deficit was evident as soon as $5 \mathrm{~min}$ after training. There was no evidence of retention $30 \mathrm{~min}$ after training. That the retention deficit in previsual rats is due to the inaccessibility, rather than the unavailability, of the memory for the AR is indicated in the work of Spear and Smith (1978). These investigators were able to get 24-h retention of an active AR in 9- and 12-dayold rats if the rats' memories were reactivated during the retention interval.

Retroactive interference often has been suggested as the prime determinant of memory inaccessibility (e.g., Miller $\&$ Berk, 1979). Since previsual rats are typically returned to the home cage during the retention interval, home cage environmental stimuli may be the primary source of

Reprint requests should be sent to James R. Misanin, Department of Psychology, Susquehanna University, Selinsgrove, PA 17870. retroactive interference for these animals. Thus, the purpose of the present study was to determine whether home cage environmental stimuli interfered with retention of the $A R$ in previsual rats.

There are at least two reasons to suspect that the home environment may be a source of interference (Misanin et al., in press). First, previsual rats are poikilothermic, and, hence, their body temperature may drop over the course of training. When they are returned to their home cages during the retention interval, they may be rewarmed by the rat dam. Thus, when reintroduced into the avoidance situation, they may be in a different state from that in which learning took place, and proper retrieval cues may not be accessible. Similarly, emotional level may be an important retrieval cue and at the end of training may be substantially different from what it was at the end of the retention interval.

\section{METHOD}

\section{Subjects}

Thirty 10-day-old albino Wistar rats were the subjects in this experiment. They were born in the university animal colony and kept with their mothers on pine shavings in $46 \times 23 \times 13 \mathrm{~cm}$ polyethylene cages prior to training. Equal numbers of males and females were used. A split-litter technique was employed.

\section{Apparatus}

The apparatus consisted of a 10.5 -cm-square grid floor surrounded by $2.5-\mathrm{cm}$-high acrylic walls, at the top of which was a 6 -cm-wide feltcovered platform. The grid floor consisted of 1-mm-diam steel rods spaced $4 \mathrm{~mm}$ apart. These rods were connected to a commercial shock generator and scrambler (Harvard Instruments Model 3121).

A $20 \times 13 \times 14 \mathrm{~cm}$ clear acrylic holding cage and a temperaturecontrolled insulated chamber were used to house some of the animals during a 30-min retention interval. The chamber was heated by a $100-$ $\mathrm{W}$ incandescent light bulb. The heat was regulated by manipulating the cover of a $8 \times 16 \mathrm{~cm}$ air vent in the top of the chamber. A Yellow- 
Springs telethermometer (Model 43 TD) was used to continuously monitor the temperature of the holding cage.

An Elab (TE-3) telethermometer and F-6 probe were used to record the rat pups' colonic temperature.

\section{Procedure}

Three animals of the same gender were selected from a litter. Each was assigned randomly to one of three groups: a 0 -min $(45-\mathrm{sec})$ retention group, a 30-min retention group (HC) that was returned to the home cage during the retention interval, and a 30-min retention group (NHC) that was kept in the holding cage in the heated chamber during the retention interval.

During both training and the test for retention, each rat was given 30 avoidance trials. A trial began when a rat was placed in the center of the grid floor. The rat then had $15 \mathrm{sec}$ in which to avoid shock by climbing onto the felt-covered platform. A climb was said to have occurred when a rat had three feet on the platform or all four feet off the grids. If the rat failed to make an AR, a .1-mA $60-\mathrm{Hz}$ ac shock was applied to the grid floor. The shock continued until the rat climbed onto the platform or until $180 \mathrm{sec}$ had elapsed. If an animal failed to escape in the $180 \mathrm{sec}$, its forepaws were placed on the platform and it was gently pushed onto the platform. At the end of a trial, the rat was held in the experimenter's closed hand for a 45-sec intertrial interval. The response measure analyzed was the number of ARs per five-trial block.

Colonic temperatures of all rats were taken immediately before and after acquisition and immediately before the retention test.

\section{RESULTS}

The number of ARs per five-trial block during acquisition was computed for each rat and averaged for groups; results are depicted in Figure 1. A split-plot factorial ANOVA performed on these data with the significance level set at .05 yielded only a significant main effect of trial block $[\mathrm{F}(5,40)=18 \cdot 36]$. Figure 2 shows the number of ARs per five-trial block during the retention test for each of the three groups. A split-plot factorial ANOVA performed on these data with the significance level set

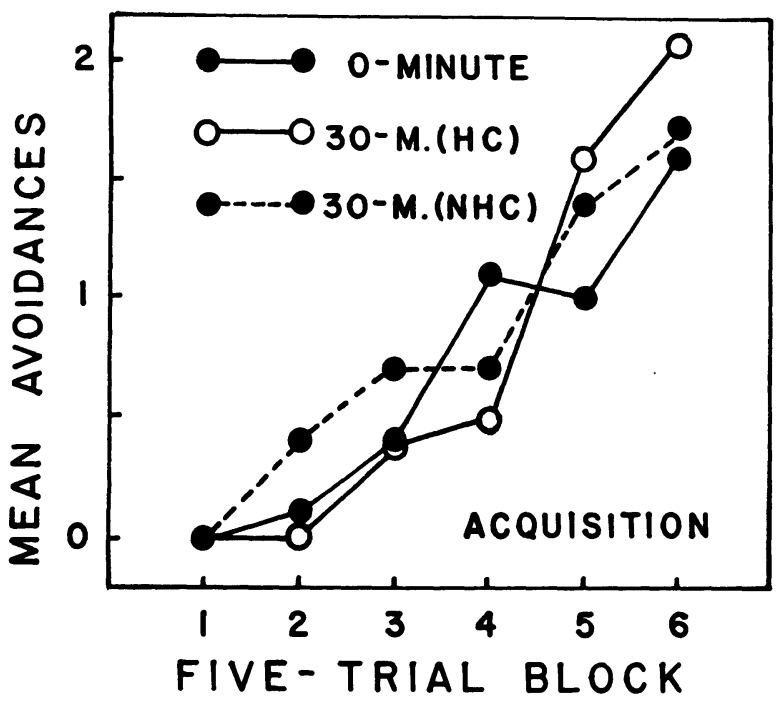

Figure 1. Mean number of avoidance responses per five-trial block during acquisition as a function of length of retention interval and treatment during the retention interval.

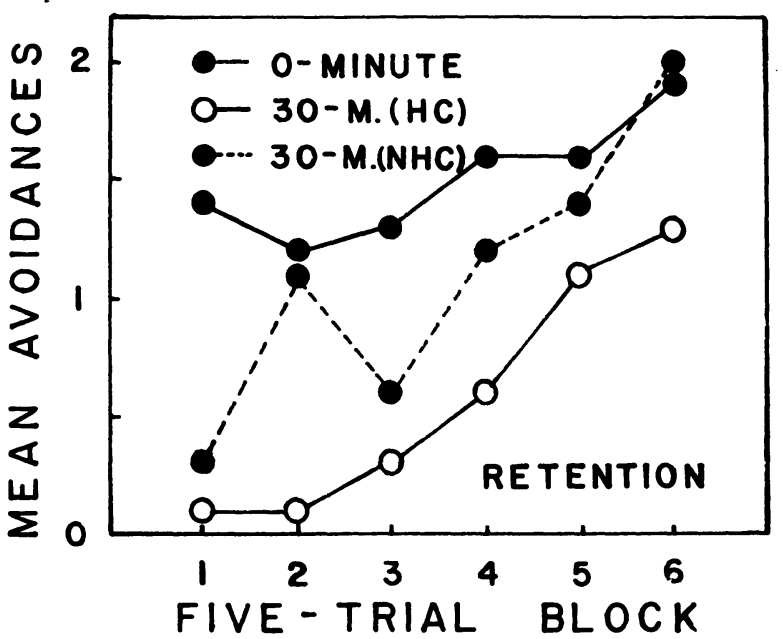

Figure 2. Mean number of avoidance responses per five-trial block during the test for retention as a function of length of retention interval and the treatment during the retention interval.

at .05 yielded significant main effects of group treatment during the retention interval $[\mathrm{F}(2,16)=11.93]$ and trial block $[F(5,40)=11.49]$. Comparisons following the ANOVA showed that the 30 -min retention groups differed significantly from the 0 -min retention group $[\operatorname{Fs}(1,16)>$ $4.52]$ and from each other $[F(1,16)=7.56]$, indicating that both groups suffered a retention deficit. Furthermore, the number of ARs made by the 30-min retention group that was returned to the home cage did not differ from their ARs during acquisition $[t(9)=1.2]$, indicating retention loss was complete in these animals. In contrast, both the 0 -min retention group and the 30-min retention group that was not returned to the home cage during the retention interval performed more ARs during the test for retention than during acquisition $[\operatorname{ts}(9)>2.5]$, indicating significant retention in both groups. Thus, although it did not prevent a retention deficit, not returning the rat pups to the home cage significantly attenuated retention loss. These results suggest that the home environment is a potential source of retroactive interference.

Comparison of colonic temperatures before and after acquisition showed no significant change in temperature for any group $[\operatorname{ts}(9)<1.96]$, indicating that the handling procedure during the intertrial interval was effective in offsetting temperature drop. Comparison of the mean colonic temperatures of the 30-min retention groups at the end of training $\left(\mathrm{HC}=31.3^{\circ} \mathrm{C}, \mathrm{NHC}=31.8^{\circ} \mathrm{C}\right)$ and the beginning of testing $\left(\mathrm{HC}=32.7^{\circ} \mathrm{C}\right.$, NHC $=$ $32.7^{\circ} \mathrm{C}$ ) also failed to show a change in temperature [ts(9) $<1.65$ ]. This suggests that a change in temperature from training to testing is not a critical factor in the retention deficit observed in the $30-\mathrm{min}$ retention groups. There was also no significant difference $[\operatorname{ts}(9)<1.0]$ in the body temperatures of the two 30 -min retention groups at the beginning $\left(\mathrm{HC}=32.4^{\circ} \mathrm{C}, \mathrm{NHC}=32.3^{\circ} \mathrm{C}\right)$ or end of training or at the beginning of testing, indicating that the 
difference in the retention of the AR of these two groups is not temperature related.

\section{DISCUSSION}

The results of this experiment indicate that the home cage environment provides a source of interference in the retention of an active AR in previsual rats. The results further indicate that body-temperaturerelated state-dependent learning cannot account for retention loss over a 30-min interval. The body temperatures of animals that were returned to their home cages and of those that were maintained outside of their home cages were kept equal and constant from the beginning of training to the beginning of testing, yet these two groups showed differential retention deficits. The animals that were returned to their home cages showed no evidence of retention, whereas those that were maintained outside of their home cages during the retention interval showed some retention of the AR.

Although the present results rule out temperature-related statedependent learning as a critical factor in the observed retention deficits, they do not in general rule out state-dependent learning as a factor. It is possible that arousal level during acquisition is different from arousal level during the test for retention after the pups have been returned to the security of their home cages. Campbell and his associates have, in fact, shown that there is an increase in hyperactivity in infant rats between 10 and 15 days of age (Campbell \& Mabry, 1973) and that this hyperactivity is potentiated in an unfamiliar environment such as the avoidance apparatus and is attenuated in the home environment (Campbell \& Raskin, 1978). Thus, arousal level may be an important retrieval cue for recall of the AR in previsual rats and at the end of the training arousal level may be substantially different from what it is at the end of the retention interval, thereby producing a retention deficit.

\section{REFERENCES}

Campbell, B. A., \& MABry, P. D. (1973). The role of catecholamines in behavioral arousal during ontogenesis. Psychopharmacologia, 31, 253-264.

CAmpbell, B. A., \& Raskin, L. A. (1978). Ontogeny of behavioral arousal: The role of environmental stimuli. Journal of Comparative and Physiological Psychology, 92, 176-184.

Goldman, P. S., \& TовACH, E. (1967). Behaviour modification in infant rats. Animal Behaviour, 15, 559-562.

Miller, R. R., \& BERK, A. M. (1979). Sources of infantile amnesia. In N. E. Spear \& B. A. Campbell (Eds.), Ontogeny of learning and memory. Hillsdale, $\mathrm{NJ}$ : Erlbaum.

Misanin, J. R., Turns, L. E., \& Hinderliter, C. F. (in press). Acquisition and retention of active avoidance behavior in previsual rats. American Journal of Psychology.

SPEAR, N. E., \& SMith, G. J. (1978). Alleviation of forgetting in preweanling rats. Developmental Psychobiology, 11, 513-529.

(Manuscript received for publication November 23, 1984.) 